\title{
Paramedian nasal cleft
}

INSERM

\section{Source}

INSERM. (1999). Orphanet: an online rare disease and orphan drug data base.

Paramedian nasal cleft. ORPHA:141242

Paramedian nasal cleft is a rare developmental defect during embryogenesis

characterized by a unilateral or bilateral coloboma of the nose, rang ing in severity from a small notch, resulting in minor deviation of the nasal septum, to variable-sized clefts of the nasal ala which may be associated with small cysts or sinuses in the nasal midline. Defect may be isolated or may occur in association with cleft lip and/or other craniofacial anomalies (e.g. hypertelorism, broadening of nasal root, midline cleft). Dorsum and apex of nose are usually well preserved. 